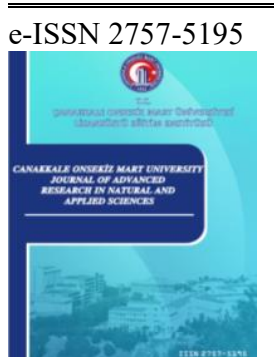

Çanakkale Onsekiz Mart University

Journal of Advanced Research in Natural and Applied Sciences

Open Access

\title{
Influence of A Novel Catalysis on The Pyrolysis Yields Obtained by Two Different Reactors
}

\author{
Mert K1lınçel $^{1, *}$, Ethem Toklu ${ }^{1}$, Fikret Polat ${ }^{1}$ \\ ${ }^{1}$ Department of Mechanical Engineering, Faculty of Engineering, Duzce University, Duzce, Turkey
}

\begin{abstract}
Article History
Received: $\quad 10.03 .2020$

Accepted: $\quad 19.08 .2020$

Published: $\quad 29.12 .2020$
\end{abstract}

Research Article

\begin{abstract}
In the present study mixtures of polymeric and cellulosic biomass materials were pyrolized in the presence of two different catalysts (sepiolite and aluminium bauxite) in various ratios by two different reactors; a rotary kiln reactor (RKR) and a fixed bed pyrolysis reactor (FBR). The results were compared to determine the effects of pyrolysis parameters such as catalysts, feedstock and reactor types on the energy content of the final products. First, the polymeric and cellulosic materials were mixed at certain ratios and thus the mixtures were prepared. Then, thermally activated catalysts were added to these mixtures. At the end of the experiments, certain properties such as higher heating value (HHV), the elemental concentrations, particle size and size surface areas of the end products (for solid and liquid phases) were calculated and analysed. The HHV of the liquid products from bauxite added mixture in RKR and FBR was $42.74 \mathrm{MJ} / \mathrm{kg}$ and $40.95 \mathrm{MJ} / \mathrm{kg}$ respectively. Besides the HHV of the oil products from sepiolite added mixture in RKR and FBR was $41.28 \mathrm{MJ} / \mathrm{kg}$ and $38.94 \mathrm{MJ} / \mathrm{kg}$ respectively. These values are same and close to HHV of the conventional diesel $(42.7 \mathrm{MJ} / \mathrm{kg})$. However no considerable effect seen on $\mathrm{HHV}$ of char products from catalyst added mixtures. On the other hand, due to the SEM images the char products it can be clearly concluded that comparing with FBR, RKR had the better performance on pyrolysis of the biomass mixtures.
\end{abstract}

Keywords - Calorimeter, catalyst, cellulose, energy conversion, higher heating value, polymer, pyrolysis.

\section{Introduction}

The rapid depletion of the main energy sources of fossil resources has brought them to nearly the end point which is one of the main issues of this century. Searching and generating alternative energy sources are crucial all around the world since the energy requirements increases gradually. Scientists are encouraged to develop novel technologies by using different energy sources such as biomass. As a sustainable energy resource, biomass, the organic matters such as straw, sawdust, wood waste, etc., can be converted to proper fuel by thermal treatments (Wan et al., 2015). Although the formation of fossil fuels takes millions years, thermochemical processes allow to produce fuel in short times from seconds to several hours (Montoya et al., 2015).

Pyrolysis which occurs at the limited levels or absence of oxygen atmosphere is the most common thermochemical process to convert the biomass into energy dense products (Anca-Couce et al., 2014; Roy et al., 2017). This process is influenced by various parameters which also influence the properties of the products in terms of quality and quantity (Tripathi et al., 2016). These parameters can be listed as biomass composition and the particle size, heating rate, operating temperature, presence of catalyst, reactor type and residence time (Foster et al., 2012; Haykiri-Acma et al., 2006; Lédé, 2013; Stefanidis et al., 2014; Zhou et al., 2013). Several

\footnotetext{
1 (1) mertkilincel@duzce.edu.tr

2 (1) ethemtoklu@duzce.edu.tr

3 (D) fikretpolat@duzce.edu.tr

*Corresponding Author
} 
related studies have also been done on pyrolysis of biomass mixtures with plastic (HDPE, PP and PET) and cellulose (paper). These studies focused on the effect of different compositions of biomass leading to product yield of pyrolysis (Chattopadhyay et al., 2016; Sebestyén et al., 2017).

In this study, the effects of the catalysts and reactor type on the end products were investigated. Sepiolite and bauxite catalysts in various ratios were mixed with biomass-plastic samples separately or in a combination. The pyrolysis experiments were performed in two different reactors; a fixed bed and a rotary kiln reactor. The energy cases of the processes were compared by determining the energy input (heating values) and outputs (calorimetric values of the products).

The main objective of this study is to investigate the effect of the aluminium bauxite as a novel catalyst on the pyrolysis of biomass in pyrolysis process.

\section{Materials and Methods}

\subsection{Feedstock}

A mixture of polymer-biomass feedstock was used for the pyrolysis experiments. Biomasses included treated paper, cardboard, towel and wood particles while polypropylene (PP), low- and high-density polyethylene (LDPE, HDPE) and polycarbonate (PC) polymeric materials were prepared. Wood biomass specimens were provided from laboratory of Wood Product Industrial Engineering, Technology Faculty, Duzce University. Polymeric biomass specimens were provided from Ernamas Company, Çankırı. Biomass particles were prepared by cutting them to finer particles about $10-20 \mathrm{~mm}$ dimensions. The dimensional properties of the feedstock are given in Table 1.

Table 1

The dimensional properties of the constituents

\begin{tabular}{ll}
\hline Constituent Name & Particle size of specimens \\
\hline $\mathrm{Sd}$ & $0.2 \mathrm{~mm}-0.6 \mathrm{~mm}$ sawdust \\
$\mathrm{Wp}$ & $10 \mathrm{~mm}-20 \mathrm{~mm}$ wood particles \\
$\mathrm{Cb}$ & $10 \mathrm{~mm}-20 \mathrm{~mm}$ cardboard particles \\
$\mathrm{Pa}$ & $10 \mathrm{~mm}-20 \mathrm{~mm}$ A4 paper particles \\
$\mathrm{PC}$ & $2-3 \mathrm{~mm}$ granular polycarbonate particles \\
$\mathrm{PP}$ & $3-4 \mathrm{~mm}$ granular polypropylene particles \\
$\mathrm{LDPE}$ & $3-4 \mathrm{~mm}$ granular low-density polyethylene particles \\
$\mathrm{HDPE}$ & $3 \mathrm{~mm}$ granular high-density polyethylene particles \\
$\mathrm{Ct}$ & $10 \mathrm{~mm}-20100 \%$ cotton towel \\
$\mathrm{St}$ & $400-600 \mathrm{~nm}$ sepiolite particles \\
$\mathrm{Bt}$ & $400-600 \mathrm{~nm}$ bauxite particles \\
\hline
\end{tabular}

Two different mixtures were created by adding certain proportions of these materials. First mixture contained $13.71 \%$ of polymer materials while the second mixture contained $41.08 \%$ of polymer materials. Sepiolite and bauxite catalysts with particle size of $5-10 \mu \mathrm{m}$ were added to these mixtures in $15 \%(\mathrm{w} / \mathrm{w})$ and six different mixtures were obtained.

Before used in the experiments, an activation process were applied to the catalysts to increase the surface areas (Salan, 2014). First the powdered samples were washed on a magnetic stirrer in a beherglas with distilled water at room temperature. The washed samples were filtered under vacuum with a $90 \mathrm{~mm}$ diameter filtration filter with $2-4 \mu \mathrm{m}$ pore size. The filtered specimens were dried at $105^{\circ} \mathrm{C}$ for 36 hours. The dried samples cooled at room temperature. In the next step, samples were mixed in the ratio of $1 \mathrm{~g}$ catalysts to $10 \mathrm{~mL}$ of $2 \mathrm{M} \mathrm{HCl}$ solution and stirred at $200 \mathrm{rpm}$ via heat assisted magnetic stirrer for 3 hours. Samples cooled to room temperature and washed via distillate water. Samples were filtered (Filter-Lab 1244- $90 \mathrm{~mm} \varnothing, 80 \mathrm{gr} / \mathrm{m}^{2}, 2-4 \mu \mathrm{m}$ pore) and washed until the $\mathrm{pH}$ of the filtered water became neutral. Neutralized samples were dried at $104^{\circ} \mathrm{C}$ 
for 36 hours. Dried samples were calcined at $550{ }^{\circ} \mathrm{C}$ for 2 hours. After these processes, samples were kept in desiccator until the experiments began.

The biomass mixtures were prepared and named as FM, FMS, FMB, RM, RMS, and RMB. F and R indicate the reactor types of FBR and RKR, respectively. The contents of the mixture samples are given in Table 2 .

Table 2

Constituent percentage of the mixtures (CPM's)

\begin{tabular}{lcccccccccccc}
\hline \multirow{2}{*}{ CPM's } & $\begin{array}{c}\text { FM1 } \\
(\%)\end{array}$ & $\begin{array}{c}\text { FM2 } \\
(\%)\end{array}$ & $\begin{array}{c}\text { FMS1 } \\
(\%)\end{array}$ & $\begin{array}{c}\text { FMS2 } \\
(\%)\end{array}$ & $\begin{array}{c}\text { FMB1 } \\
(\%)\end{array}$ & $\begin{array}{c}\text { FMB2 } \\
(\%)\end{array}$ & $\begin{array}{c}\text { RM1 } \\
(\%)\end{array}$ & $\begin{array}{c}\text { RM2 } \\
(\%)\end{array}$ & $\begin{array}{c}\text { RMS1 } \\
(\%)\end{array}$ & $\begin{array}{c}\text { RMS2 } \\
(\%)\end{array}$ & $\begin{array}{c}\text { RMB1 } \\
(\%)\end{array}$ & $\begin{array}{c}\text { RMB2 } \\
(\%)\end{array}$ \\
\hline Sd & 23.97 & 6.85 & 20.38 & 5.82 & 20.38 & 5.82 & 23.97 & 6.85 & 20.38 & 5.82 & 20.38 & 5.82 \\
Wp & 31.51 & 31.5 & 26.78 & 26.78 & 26.78 & 26.78 & 31.51 & 31.5 & 26.78 & 26.78 & 26.78 & 26.78 \\
Cb & 10.27 & 6.85 & 8.73 & 5.82 & 8.73 & 5.82 & 10.27 & 6.85 & 8.73 & 5.82 & 8.73 & 5.82 \\
Pa & 10.27 & 3.42 & 8.73 & 2.91 & 8.73 & 2.91 & 10.27 & 3.42 & 8.73 & 2.91 & 8.73 & 2.91 \\
PC & 3.42 & 10.27 & 2.91 & 8.73 & 2.91 & 8.73 & 3.42 & 10.27 & 2.91 & 8.73 & 2.91 & 8.73 \\
PP & 3.42 & 10.27 & 2.91 & 8.73 & 2.91 & 8.73 & 3.42 & 10.27 & 2.91 & 8.73 & 2.91 & 8.73 \\
LDPE & 3.42 & 10.27 & 2.91 & 8.73 & 2.91 & 8.73 & 3.42 & 10.27 & 2.91 & 8.73 & 2.91 & 8.73 \\
HDPE & 3.42 & 10.27 & 2.91 & 8.73 & 2.91 & 8.73 & 3.42 & 10.27 & 2.91 & 8.73 & 2.91 & 8.73 \\
Ct & 10.27 & 10.27 & 8.73 & 8.73 & 8.73 & 8.73 & 10.27 & 10.27 & 8.73 & 8.73 & 8.73 & 8.73 \\
St & - & - & 15.00 & 15.00 & & - & - & - & 15.00 & 15.00 & & - \\
Bt & - & - & - & - & 15.00 & 15.00 & - & - & - & - & 15.00 & 15.00 \\
\hline
\end{tabular}

All the mixtures were prepared with precision scales $(0.0001 \mathrm{~g}$ sensitivity).

\subsection{Pyrolysis}

A laboratory-scale fixed bed pyrolysis reactor (FBR) and a rotary kiln pyrolysis reactor (RKR) were used in the pyrolysis experiments. All the experiments were maintained at $\mathrm{N}_{2}$ atmosphere and at maximum temperature of $520 \pm 20^{\circ} \mathrm{C}$. The operating pressure values were equal with the ambient atmosphere Both FBR and RKR. This is why the RKR was continuous system and the FBR had an outline pipe for exhaust excessive gas.

The RKR is a ready to use system (Proterm RTR 11/100/500) which operates at $3 \mathrm{~kW}$ and a voltage of $220 \mathrm{~V}$. The working volume of the inner cylinder is a quartz material, having $114 \mathrm{~mm}$ diameter and $150 \mathrm{~mm}$ length. The schematic diagram and the snapshot are given in Figure 1 (a-b).

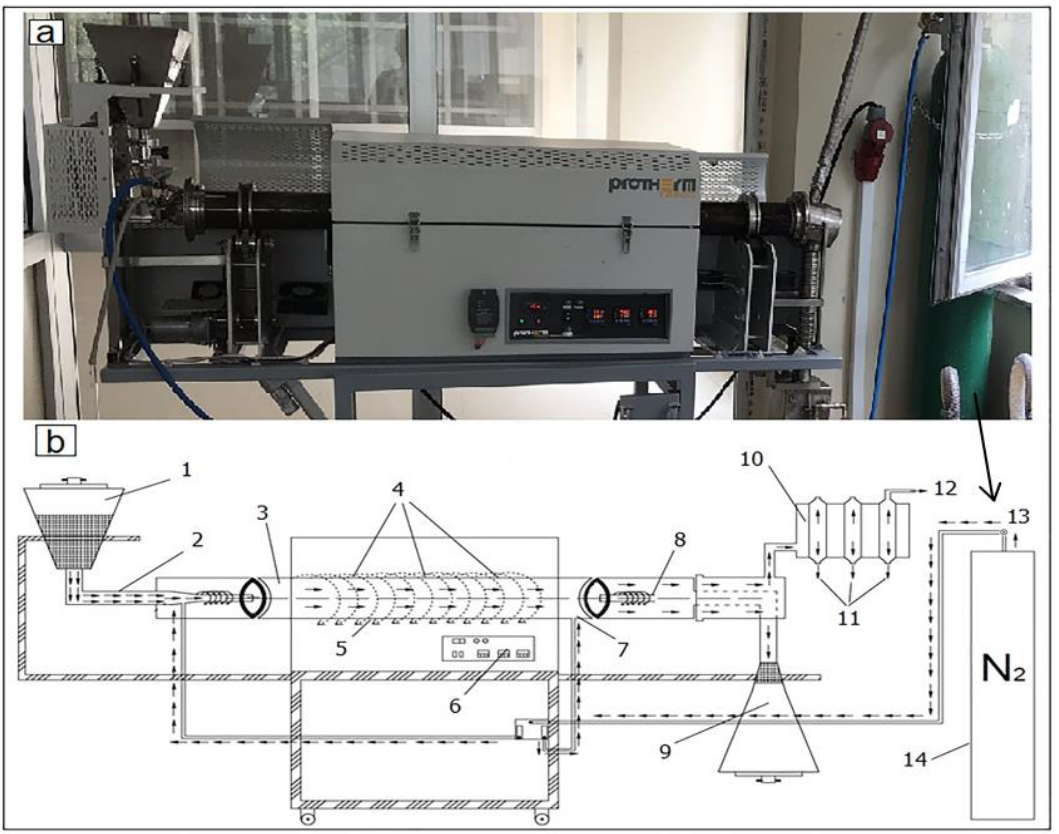

Figure 1. (a) Schematic diagram, (b) picture of the RKR

(1: sample inlet, 2: vibrational inlet conveyor, 3 and 7: $\mathrm{N}_{2}$ inlet, 4: k-type temperature sensors, 5: quartz pyrolysis reactor, 6: data controller, 8: vibrational outlet conveyor, 9: char collection tank, 10: condenser, 11: pyrolysis oil outlet, 12: syngas outlet, 13:regulator for $\mathrm{N}_{2}$ tank, 14: 50 L Cylinder 230 bar $\mathrm{N}_{2}$ concave tank) 
Figure 2 (a-b) shows the schematic diagram and picture of FBR pyrolysis system. The system was constructed from the 304 stainless steel material. The inner cylinder has $114 \mathrm{~mm}$ diameter, $150 \mathrm{~mm}$ length and $7 \mathrm{~mm}$ thickness. In order 2to supply the $\mathrm{N}_{2}$ to the system, a $5 \mathrm{~mm}$ diameter cylindrical pipe extending from the nipple to the base of the unit was connected. The extension of the pipe to the bottom of the unit was also done to ensure an inert atmosphere in the whole unit. A K-Type thermocouple was used for the temperature measurements.

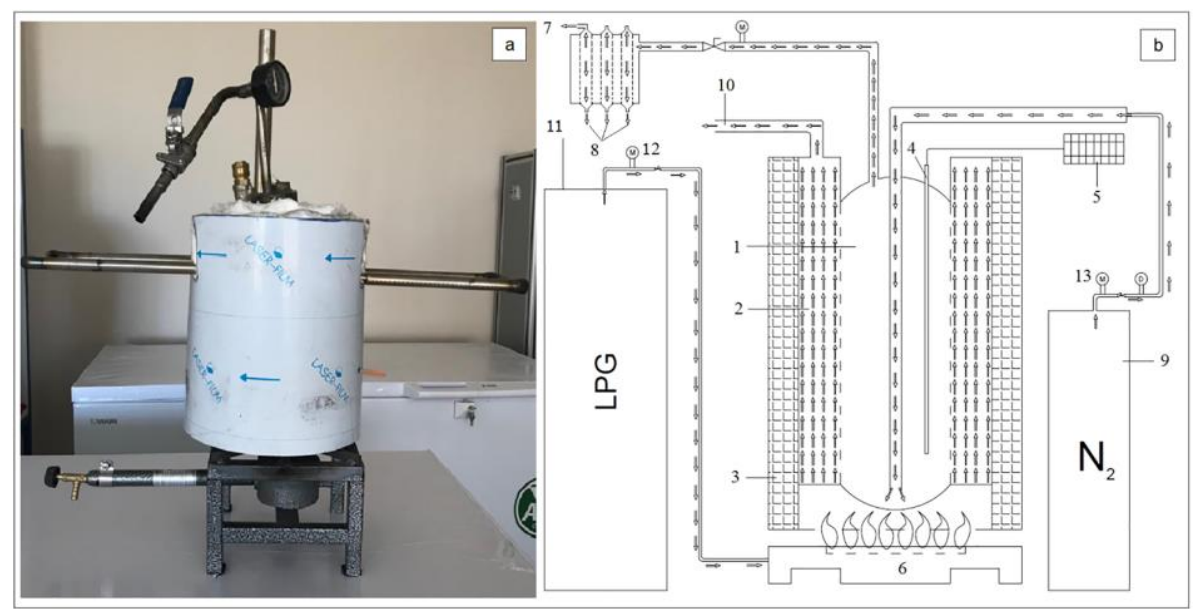

Figure 2. (a) Schematic diagram, (b) picture of the FBR (1: pyrolysis vessel, 2: burning gas smoke exhaust path, 3: $50 \mathrm{~mm}$ glass wool insulation, 4: temperature sensor (K-type termokupl), 5: temperature data logger, 6: burner, 7: syngas exhaust, 8: pyrolysis oil outlet (condenser), 9: 10 L Cylinder 200 bar $\mathrm{N}_{2}$ concave tank, 10: burning gas smoke exhaust, 11: LPG cylinder, 12: regulator for LPG, 13: regulator for $\mathrm{N}_{2}$ tank)

$100 \mathrm{~g}$ sample was fed into the reactor and pyrolized at the desired temperature for $120 \mathrm{~min}$. The heating rate was about $10{ }^{\circ} \mathrm{C} / \mathrm{min}$ until the reactor reach the temperature of $520 \pm 20^{\circ} \mathrm{C}$. Because of the heating process in the FBR realized via LPG, the heating rate was constant. Thus, considering the heating-up time the residence time was $130 \pm 2 \mathrm{~min}$ for whole experiments. An inert atmosphere was provided by the inert gas $\mathrm{N}_{2}$ with 20 $\mathrm{ml} / \mathrm{min}$ flow rate. The rotation rate and the slope of the RKR were set to $3 \mathrm{rpm}$ and $10^{\circ}$ respectively. Water circulating chiller system was used outlet of the both reactors to transform the produced organic vapours into liquid phase. The exhaust gaseous flew through the pipe to the chiller system. Thus, the liquid phase of products collected. At these conditions, the experimental synchronization was provided for both reactor types. All the experiments were repeated for three times. These three percentages of the product yields were determined by taking the average of the weights obtained from the experiments and tests.

The obtained solid and liquid products were analysed with Fourier transform infrared spectroscopy-FTIR (Shimadzu- IR Prestige 21), calorimeter (IKA 5003 oxygen bomb calorimeter), scanning electron microscopySEM (FEI- Quanta FEG 250), brauner emmett teller-BET (Quantachrome Autosorb) and X-ray fluorescenceXRF (Spectro Xepos II). Gaseous yields were only calculated by subtracting the mass of liquid and solid from the total mass of feedstock as they cannot be analysed by our system. 


\section{Results and Discussion}

\subsection{Catalysts' Characterizations}

Several processes were applied to the catalysts to obtain thermally active catalysts and to enhance the surface areas of the catalysts. BET surface area measurements were realized before and after of the activation process for both catalysts. While the process surface area of the sepiolite catalyst was increased about 9 times, bauxite catalyst was increased about 10 times. These increases indicate that the penetration properties were enhanced for both catalysts. The surface area analyses of the catalysts are given in Table 3. Similarly, according to the SEM images, it can be concluded that the particles of the both catalysts were become finer. It also shows that char products have finer particles in mixtures with catalyst comparing to the mixtures without catalyst. SEM images of the both catalysts before and after the activation process are given in Figure 3. Due to the increase of the surface areas of the catalysts, the contact surfaces of the catalysts were increased and accordingly the penetration degrees were increased. Besides, SEM images showed that the particle sizes of the catalysts were reduced from 50-100 $\mu \mathrm{m}$ to $5-10 \mu \mathrm{m}$. These reductions also indicate the increment of surface areas of the catalysts. XRF analyses were also performed to determine the chemical component and oxide concentrations of the catalysts. Table 4 shows these concentrations before and after the activation treatment. These concentrations indicate that the activation processes were increase the $\mathrm{SiO}_{2}$ concentration in sepiolite while reducing them for bauxite. It can be interpreted the activation processes were effective for sepiolite on this perspective. On the other hand, it seems to the activation process not effective for the bauxite catalysts.

Table 3

BET surface analysis of the catalysis

\begin{tabular}{lrr}
\hline & \multicolumn{2}{c}{ BET Surface Area $\left(\mathrm{m}^{2} / \mathrm{g}\right)$} \\
\cline { 2 - 3 } Catalysts & Before Activation & After Activation \\
\hline Sepiolite & 19.90 & 189.99 \\
Bauxite & 7.50 & 81.01 \\
\hline
\end{tabular}

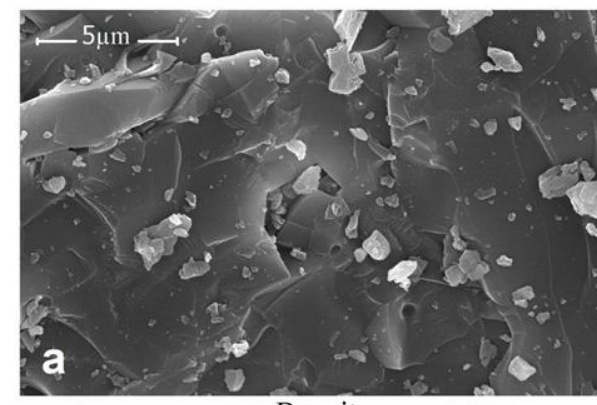

Bauxite

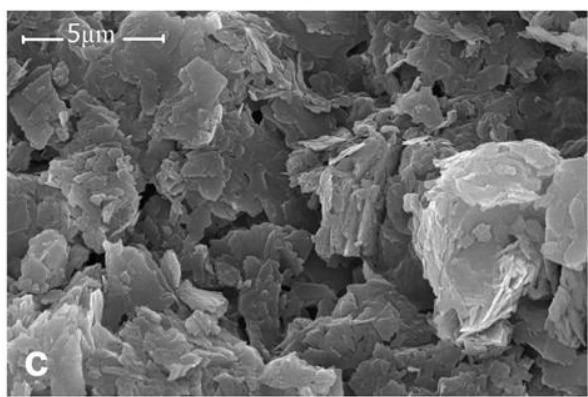

Sepiolite

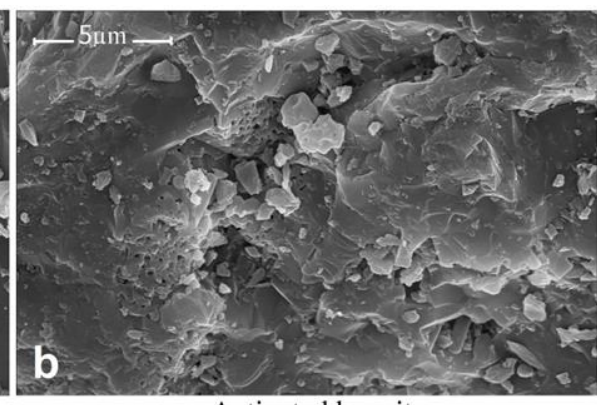

Activated bauxite

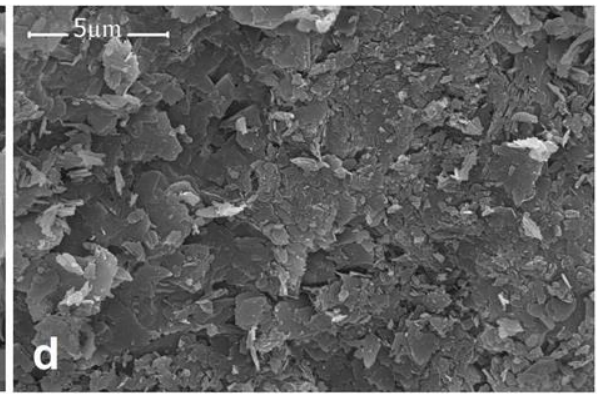

Activated sepiolite

Figure 3. SEM images of the catalysts. (a), (b), (c), (d) 
Table 4

The concentrations of catalysts

\begin{tabular}{|c|c|c|c|c|c|}
\hline \multirow[t]{2}{*}{ Oxide } & \multirow[t]{2}{*}{ Element } & \multicolumn{4}{|c|}{ Concentration $(\%)$} \\
\hline & & Sepiolite & Active sepiolite & Bauxite & Activated bauxite \\
\hline $\mathrm{SiO}_{2}$ & Silicon & 65.88 & 90.33 & 8.901 & 9.866 \\
\hline $\mathrm{MgO}$ & Magnesium & 32.74 & 0.6355 & 0.388 & 0.2577 \\
\hline $\mathrm{CaO}$ & Calcium & 0.6348 & 0.1722 & 0.5416 & 0.1553 \\
\hline $\mathrm{Fe}_{2} \mathrm{O}_{3}$ & Iron & 0.2772 & 0.4543 & 1.385 & 1.392 \\
\hline $\mathrm{K}_{2} \mathrm{O}$ & Potassium & 0.2557 & 0.8288 & 0.2208 & 0.1947 \\
\hline $\mathrm{SO}_{3}$ & Sulfur & 0.04318 & - & 0.02588 & \\
\hline $\mathrm{Na}_{2} \mathrm{O}$ & Sodium & 0.031 & 0.843 & 0.079 & \\
\hline $\mathrm{TiO}_{2}$ & Titanium & 0.0302 & 0.0922 & 3.584 & 4.431 \\
\hline $\mathrm{V}_{2} \mathrm{O}_{5}$ & Vanadium & 0.0246 & - & 0.0284 & 0.036 \\
\hline $\mathrm{Al}_{2} \mathrm{O}_{3}$ & Aluminum & 0.0077 & - & 87.22 & 85.74 \\
\hline $\mathrm{MnO}$ & Manganese & 0.00282 & 9.564 & - & \\
\hline $\mathrm{Cr}_{2} \mathrm{O}_{3}$ & Chromium & 0.0014 & - & 0.03303 & 0.04281 \\
\hline $\mathrm{P}_{2} \mathrm{O}_{5}$ & Phosphorus & 0.0012 & 0.01395 & 0.1972 & 0.1551 \\
\hline $\mathrm{Ba}$ & Barium & - & 0.01772 & - & \\
\hline $\mathrm{ZrO}_{2}$ & Zirconium & - & 0.0124 & 0.1447 & 0.1897 \\
\hline $\mathrm{SrO}$ & Strontium & . & - & 0.0815 & 0.05571 \\
\hline
\end{tabular}

\subsection{Sample Characterizations}

The FTIR analyses were performed to confirm that the materials were polymeric and cellulosic. The FTIR characteristics of the samples are given in Figure 4. The results were compared with the material library of the analyser and the properties of the materials were confirmed. According to the wavenumbers obtained from the FTIR analysis, the properties of the feedstock are verified.

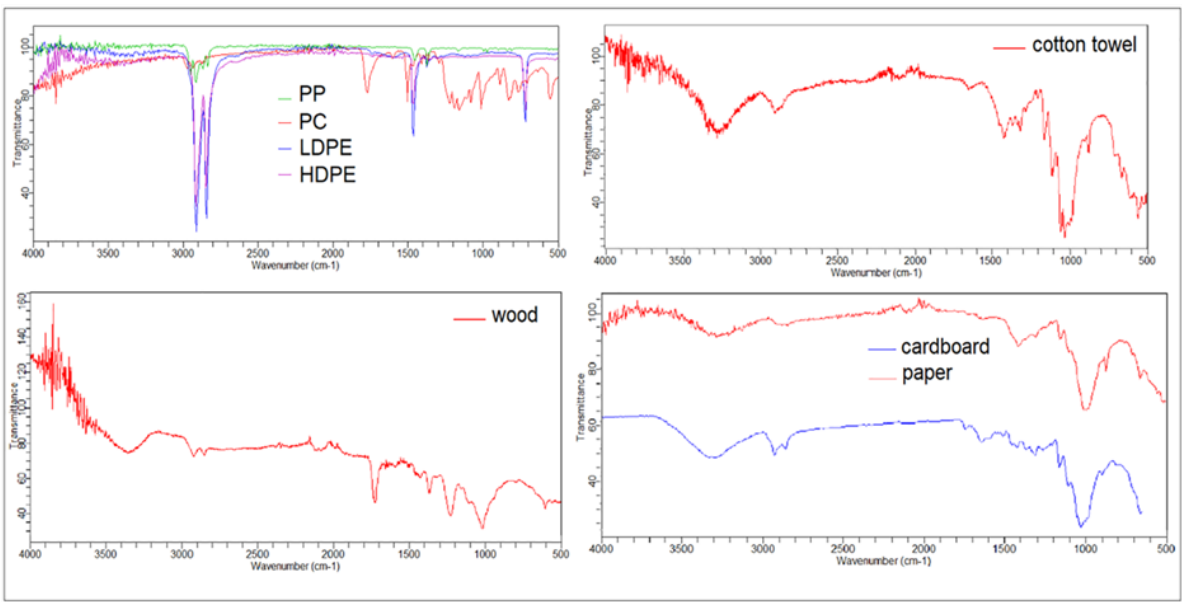

Figure 4. FTIR analysis of the feedstock

On the other hand, the higher heating values (HHV) of the untreated samples were determined with a bomb calorimeter. Test samples were prepared and tested according to ASTM E711-87 specifications. Tests were conducted using IKA C5003 universal testing machine via using 0,1g samples. The primary goal was to calculate the total energy contents of the mixtures. According to the results of tests, HHV's of the untreated samples are given in Table 5 . 
Table 5

The HHV of the untreated samples

\begin{tabular}{lrrr}
\hline Sample & Weight of the sample $(\mathrm{g})$ & HHV $(\mathrm{cal} / \mathrm{g})$ & $\mathrm{HHV}(\mathrm{MJ} / \mathrm{kg})$ \\
\hline $\mathrm{Sd}$ & 0.1010 & 4542 & 19.02 \\
$\mathrm{Wp}$ & 0.1021 & 4380 & 18.34 \\
$\mathrm{Cb}$ & 0.1040 & 4155 & 17.40 \\
$\mathrm{~Pa}$ & 0.1023 & 1683 & 7.05 \\
$\mathrm{PC}$ & 0.1016 & 7165 & 30.00 \\
$\mathrm{PP}$ & 0.1025 & 10031 & 42.00 \\
$\mathrm{LDPE}$ & 0.1023 & 6071 & 25.42 \\
$\mathrm{HDPE}$ & 0.1035 & 9792 & 41.00 \\
$\mathrm{Ct}$ & 0.1024 & 3477 & 14.56 \\
\hline
\end{tabular}

\subsection{Products Yields}

$0.0001 \mathrm{~g}$ precision scale was used while preparing mixtures. At the end of the experiments the weights of char and oil products were determined via this scale. Pyrolysis yield obtained from FBR and RKR are shown in Figure 5 and Figure 6 respectively.

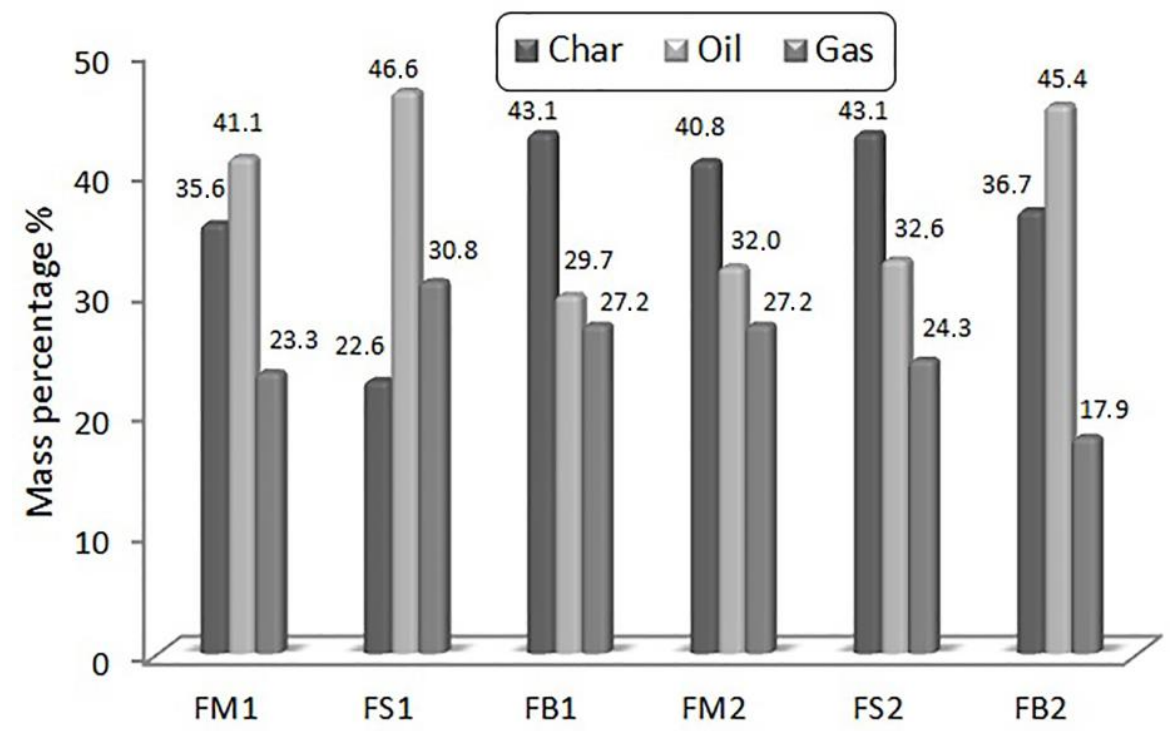

Figure 5. Pyrolysis yield from fixed bed reactor

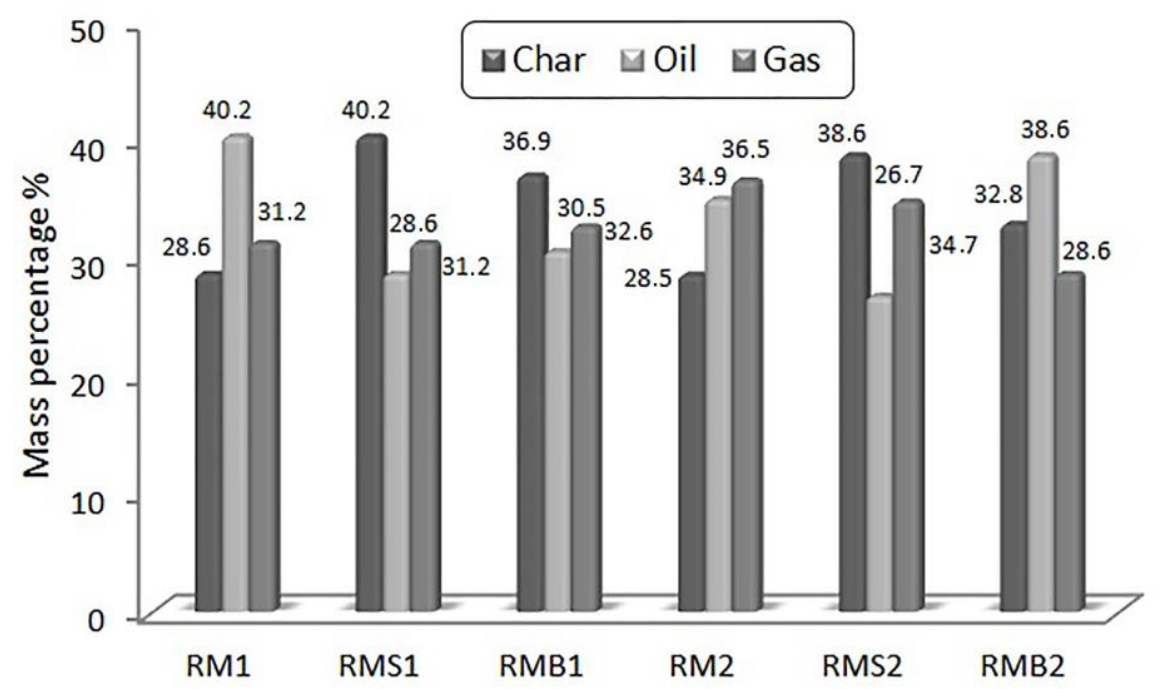

Figure 6. Pyrolysis yield from rotary kiln reactor 
According to the yield distribution, the high yield of oil product was obtained in the presence of bauxite catalyst in FBR. On the other hand, the higher oil yield product was obtained in the catalyst-free mixtures in RKR even though it is not a big difference. However, the presence of the bauxite catalyst in the polymer rich mixtures in the RKR resulted with an increase in the amount of oil product yields. Besides, it is clearly observed that the sepiolite catalyst affects the formation of oil products positively in the cellulose rich mixture in the FBR. The maximum oil product yields for the pyrolysis of FS1 and FB2 were observed $46.6 \%$ and $45.4 \%$, respectively. However, no linear increase or decrease was observed between the product yields due to the usage of the catalysts. The maximum char formation was seen in FB1 and FS2. This is thought to be due to the effective transformation in FBR. Since there is no similar study on pyrolysis of biomass mixture with these contents, the results were more selective. However, several studies about the effect of the catalysts on product yield of pyrolysis of biomass have reported similar observations (maximum liquid oil 40\%, char $40 \%$ and $20 \%$ gas). According to these studies, the usage of catalysts increased the char and gas product yields while decreasing the oil product yield (Tripathi et al., 2016). Generally, it is thought that the reason for this is the several characteristic of the catalyst which controls the formation and transformation of hydrocarbon molecules (Tripathi et al., 2016). Similarly, several studies have also reported that the maximum liquid oil yield was $32 \%$ while minimum yield of liquid oil was $20 \%$ with the usage of catalysts of $\mathrm{Al}_{2} \mathrm{O}_{3}$ and zeolite (H-SDUSY) respectively.

\subsection{Product's Characterizations}

\subsubsection{Char}

The char residues were collected at the end of the processes. SEM images of these char residues were taken, and the particle sizes were determined. Figure 7 and 8 shows the SEM images of char products form RKR and FBR respectively. It can be concluded from the images that the polymer rich mixtures were cracked better than the cellulose rich mixtures. It's known that the usage of catalyst during the pyrolysis process has positive effect on the yield and quantity of the end products. Similarly, according to the images, the catalysis had positive effect on the cracking the materials. The type of the reactor is a considerable parameter which influences properties of pyrolysis products during the pyrolysis process (Tripathi et al., 2016). Comparing with the FBR the particle sizes of the char products from RKR were finer as expected. Unlike FBR, the reactor rotated during the pyrolysis process at RKR. Due to this rotational movement, the samples were mixed homogeneously during the process. Therefore, it is expected that the particle size of the products obtained from RKR is finer than the products that obtain from FBR. The HHV of the char products was determined with a bomb calorimeter (ASTM E711-87) and is given in Table 6. According to the HHV of the char products, it is seen that the catalysts affects the HHVs of chars negatively in the both RKR and FBR.
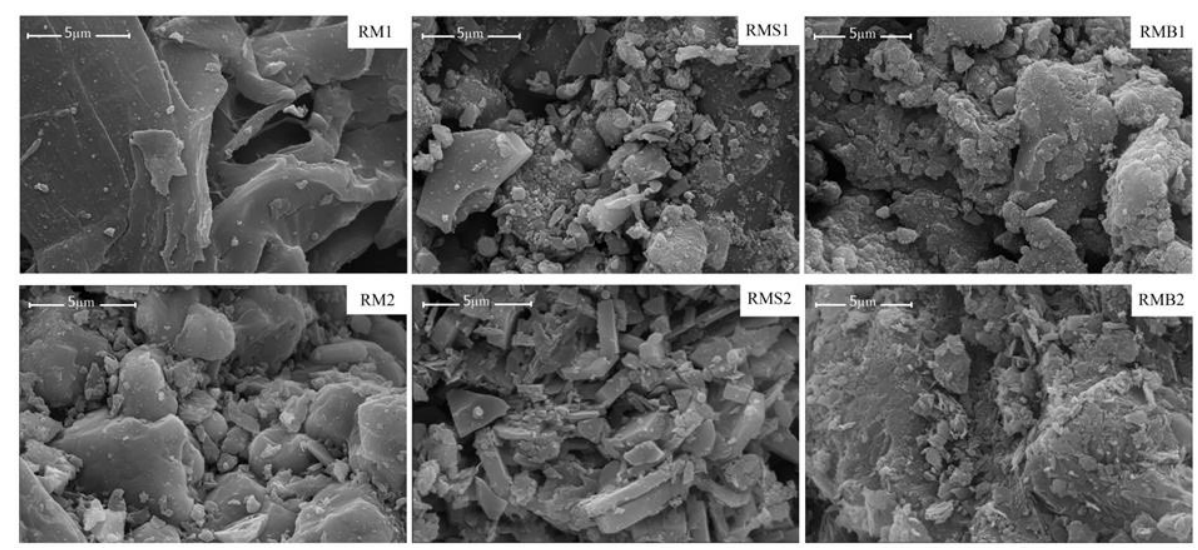

Figure 7. SEM images of the char products from RKR 


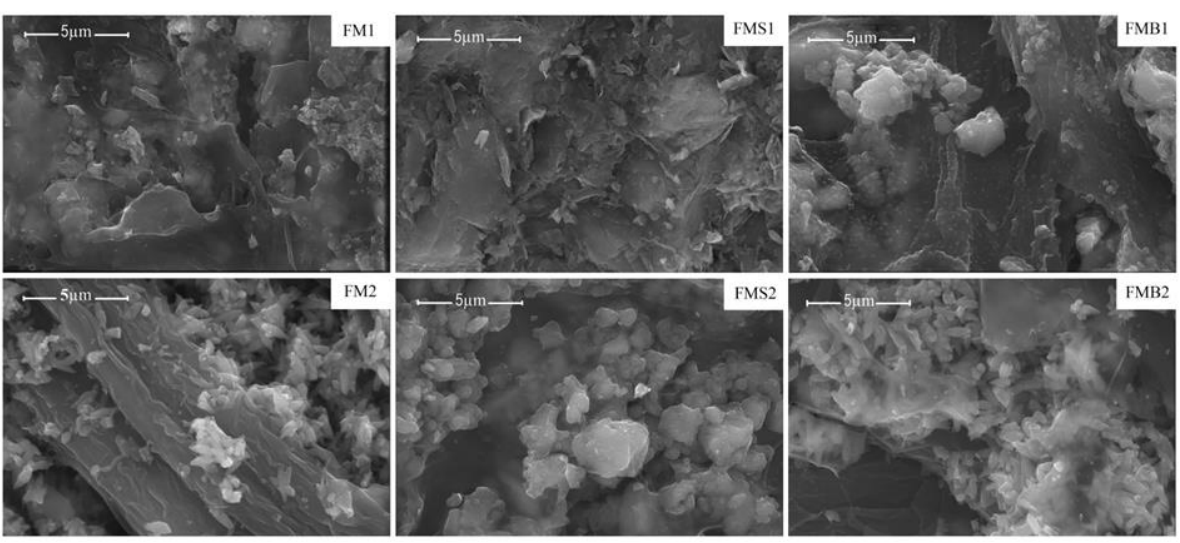

Figure 8. SEM images of the char products from FBR

Table 6

The HHV of the char products

\begin{tabular}{lrlr}
\hline Fixed bed reactor & HHV (MJ/kg) & Rotary kiln reactor & HHV $(\mathrm{MJ} / \mathrm{kg})$ \\
\hline FM1 Char & 11.30 & RM1 Char & 14.44 \\
FMS1 Char & 6.26 & RMS1 Char & 8.99 \\
FMB1 Char & 8.35 & RMB1 Char & 10.24 \\
FM2 Char & 12.41 & RM2 Char & 15.55 \\
FMS2 Char & 5.97 & RMS2 Char & 9.53 \\
FMB2 Char & 6.42 & RMB2 Char & 9.56 \\
\hline
\end{tabular}

\subsubsection{Properties of Oil Products}

The pyrolysis oil products were analyzed and HHV of the products were determined with a bomb calorimeter (ASTM D240-02). The HHVs of the oil products are given in Table 7. The catalysts affect the calorific values of the products positively. The catalysts increased the HHV of the pyrolysis oil products especially for the both RKR and the FBR, comparing with the catalysts-free mixtures. Besides, the HHV of oil products which was obtained from RKR was found to be higher than those of FBR in the mixtures with the same content. It is also thought that the process is more homogenous during the pyrolysis process takes place in the RKR thanks to the rotational movement.

Table 7

The HHV of the pyrolysis oil products

\begin{tabular}{lrlr}
\hline Fixed bed reactor & HHV $(\mathrm{MJ} / \mathrm{kg})$ & Rotary kiln reactor & HHV $(\mathrm{MJ} / \mathrm{kg})$ \\
\hline FM1 Pyrolysis oil & 34.39 & RM1 Pyrolysis oil & 36.82 \\
FMS1 Pyrolysis oil & 37.41 & RMS1 Pyrolysis oil & 38.38 \\
FMB1 Pyrolysis oil & 38.18 & RMB1 Pyrolysis oil & 40.08 \\
FM2 Pyrolysis oil & 35.81 & RM2 Pyrolysis oil & 38.07 \\
FMS2 Pyrolysis oil & 38.94 & RMS2 Pyrolysis oil & 41.28 \\
FMB2 Pyrolysis oil & 40.95 & RMB2 Pyrolysis oil & 42.74 \\
\hline
\end{tabular}

\section{Conclusion}

The pyrolysis of biomass is such an important process to obtain clean energy in an environmentally friendly manner. The process provides lots of advantages on transforming waste yields into clean and useful energy. Besides, the product yield has a wide range of use in the industry. Especially the oils and gas can be used as alternative fuels after certain pre-treatments and char products can be used as active carbon and carbon black. The catalytic pyrolysis of biomass mixtures with specific ingredients were carried out in FBR and RKR in the present study. The obtained data support that catalysts are important parameters that influence the product 
yield distribution and HHV of the oils. The HHV of the oils were observed between $34.39 \mathrm{MJ} / \mathrm{kg}$ and 38.07 $\mathrm{MJ} / \mathrm{kg}$ in catalyst-free mixtures. However, the HHV of the oils obtained from catalyst added mixtures changed between $37.41 \mathrm{MJ} / \mathrm{kg}$ and $42.74 \mathrm{MJ} / \mathrm{kg}$. These results indicate that the catalyst-added mixtures can be effectively converted into energy rich products. Besides the type of reactor has also an effect on product yield distribution. Above all of these results the major effect is obviously the feedstock. So, this effect reveals import of the classification the biomass. Depending on the feedstock the HHV values were found in different values. The HHV of the oil products from RKR were between $36.82 \mathrm{MJ} / \mathrm{kg}$ and $42.74 \mathrm{MJ} / \mathrm{kg}$ while from FBR were between $34.39 \mathrm{MJ} / \mathrm{kg}$ and $40.95 \mathrm{MJ} / \mathrm{kg}$. Comparing with the HHV of the products from two reactors, it is seen that both HHV of char and oil from RKR were higher than FBR. It can be noted that it is appropriate to use aluminium bauxite as catalyst to obtain the desired product quality and quantity on the end products of the pyrolysis processes.

\section{Acknowledgement}

The authors acknowledge the financial support from the DÜBAP-Duzce University Coordinatorship of Scientific Research Projects (Project No: 2016.06.06.405; Project Title: Improvement of Gas Production and Energy Efficiency of a Municipal Solid Waste Thermal Processing Plant).

\section{Author Contributions}

Mert Kılınçel: Collected data, performed the analysis and wrote the paper.

Ethem Toklu: Conceived and designed the analysis.

Fikret Polat: Collected data.

\section{Conflicts of Interest}

The authors declare no conflict of interest.

\section{References}

Anca-Couce, A., Mehrabian, R., Scharler, R., \& Obernberger, I. (2014). Kinetic scheme of biomass pyrolysis considering secondary charring reactions. Energy Conversion and Management, 87, 687-696. doi: 10.1016/j.enconman.2014.07.061

ASTM E711-87 Standard Test Method for Gross Calorific Value of Refuse-Derived Fuel by the Bomb Calorimeter.

ASTM D240-02 Standard Test Method For Heat Of Combustion Of Liquid Hydrocarbon Fuels By Bomb Calorimeter.

Chattopadhyay, J., Pathak, T. S., Srivastava, R., \& Singh, A. C. (2016). Catalytic co-pyrolysis of paper biomass and plastic mixtures (HDPE (high density polyethylene), PP (polypropylene) and PET (polyethylene terephthalate)) and product analysis. Energy, 103, 513-521. doi: 10.1016/j.energy.2016.03.015

Foster, A. J., Jae, J., Cheng, Y. T., Huber, G. W., \& Lobo, R. F. (2012). Optimizing the aromatic yield and distribution from catalytic fast pyrolysis of biomass over ZSM-5. Applied Catalysis A: General, 423424, 154-161. doi: 10.1016/j.apcata.2012.02.030

Haykiri-Acma, H., Yaman, S., \& Kucukbayrak, S. (2006). Effect of heating rate on the pyrolysis yields of rapeseed. Renewable Energy, 31(6), 803-810. doi: 10.1016/j.renene.2005.03.013

Lédé, J. (2013). Réacteur de pyrolyse rapide de la biomasse: Une revue de quelques verrous scientifiques et d'actions de recherches recommandées. Oil and Gas Science and Technology, 68(5), 801-814. doi: $10.2516 /$ ogst $/ 2013108$

Montoya, J. I., Valdés, C., Chejne, F., Gómez, C. A., Blanco, A., Marrugo, G., Osorio, J., Castillo, E., Aristóbulo, J., \& Acero, J. (2015). Bio-oil production from Colombian bagasse by fast pyrolysis in a fluidized bed: An experimental study. Journal of Analytical and Applied Pyrolysis, 112, 379-387. doi: 10.1016/j.jaap.2014.11.007

Roy, P., \& Dias, G. (2017). Prospects for pyrolysis technologies in the bioenergy sector: A review. Renewable and Sustainable Energy Reviews, 77, 59-69. DOI: 10.1016/j.rser.2017.03.136

Salan T., M. Hakkı Alma \& Ertuğrul Altuntaş (2019) The fuel properties of pyrolytic oils obtained from 
catalytic pyrolysis of non-recyclable pulper rejects using activated natural minerals, Energy Sources, Part A: Recovery, Utilization, and Environmental Effects, 41:12, 1460-1473, DOI: $10.1080 / 15567036.2018 .1548522$

Sebestyén, Z., Barta-Rajnai, E., Bozi, J., Blazsó, M., Jakab, E., Miskolczi, N., \& Czégény, Z. (2017). Catalytic Pyrolysis of Biomass and Plastic Mixtures Using HZSM-5 Zeolite. Energy Procedia, 105, 718-723. doi: 10.1016/j.egypro.2017.03.381

Stefanidis, S. D., Kalogiannis, K. G., Iliopoulou, E. F., Michailof, C. M., Pilavachi, P. A., \& Lappas, A. A. (2014). A study of lignocellulosic biomass pyrolysis via the pyrolysis of cellulose, hemicellulose and lignin. Journal of Analytical and Applied Pyrolysis, 105, 143-150. doi: 10.1016/j.jaap.2013.10.013

Tripathi, M., Sahu, J. N., \& Ganesan, P. (2016). Effect of process parameters on production of biochar from biomass waste through pyrolysis : A review. 55, 467-481. doi: 10.1016/j.rser.2015.10.122.

Wan, K., Wang, Z., He, Y., Xia, J., Zhou, Z., Zhou, J., \& Cen, K. (2015). Experimental and modeling study of pyrolysis of coal, biomass and blended coal-biomass particles. Fuel, 139, 356-364. doi: 10.1016/j.fuel.2014.08.069

Zhou, L., Yang, H., Wu, H., Wang, M., \& Cheng, D. (2013). Catalytic pyrolysis of rice husk by mixing with zinc oxide: Characterization of bio-oil and its rheological behavior. Fuel Processing Technology, 106, 385-391. doi: 10.1016/j.fuproc.2012.09.003 